\title{
Finanças da Subscrição Externa de Capital
}

\author{
Yuichi Richard Tsukamoto *
}

1. Capital Adicional para Aumento do Ativo Circulante. 2. Capital Adicional para Aumento do Ativo Imobilizado. 3. Capital Adicional para Substituir Empréstimos. 4. Conclusão.

A formação e o fortalecimento do capital próprio da emprêsa têm sido uma das metas principais das recentes políticas econômico-financeiras do Govêrno. Em face do desempenho extraordinário do mercado de ações, as autoridades monetárias fazem um apêlo às emprêsas para que busquem capital em vez de crédito. Certamente, o crescente interêsse de investidores brasileiros pelo mercado de ações abre grandes perspectivas à democratização do capital das emprêsas. Observamos que diversas emprêsas se aproveitaram e se aproveitarão das novas oportunidades do mercado de ações para nêle lançar suas ações novas. Estas subscrições de capital, além de democratizarem as emprêsas lançadoras, permitem-lhes realizar investimentos indispensáveis, obtendo recursos financeiros por custo inferior aos conseguidos em estabelecimentos financeiros. Os consumidores receberão os benefícios da redução dos preços, uma vez que as despesas financeiras das emprêsas deverão ser diminuídas. Tal de-

* Professor-Contratado do Departamento de Contabilidade, Finanças e Contrôle da Escola de Administração de Emprêsas de São Paulo, da Fundação Getúlio Vargas e Diretor Executivo da Companhia Paulista de Fertilizantes COPAS.
R. Adm. Emp.,
Rio de Janeiro,
10(2): 115-127, jul./set. 1970 
mocratização das emprêsas contribuirá para a política de combate à inflação e fortalecerá o regime econômico do país.

Entretanto, existe um aspecto que merece a atenção dos dirigentes das emprêsas que realizam o aumento de capital através de novas emissões. Trata-se das responsabilidades assumidas pelas emprêsas lançadoras de ações de remunerar satisfatòriamente os novos acionistas. Neste artigo apresentamos, com exemplos concretos, as finanças da subscrição externa de capital, demonstrando as responsabilidades financeiras adicionais que as emprêsas devem assumir para retribuir os novos acionistas. A obtenção de recursos financeiros através de subscrição de ações novas cria extensas responsabilidades de remunerar o nôvo capital. Se não existirem as condições necessárias para o cumprimento de tais responsabilidades, as emprêsas não devem lançar as novas açőes no mercado financeiro. $O$ aproveitamento indevido dessa nova oportunidade no mercado de ações poderá levar os novos investidores a uma grande ilusão, contribuindo negativamente para o desenvolvimento bolsista do Brasil.

Para exemplificarmos as finanças da subscrição externa de capital tomamos como pressupostos os seguintes fatôres:

$\begin{array}{rrr}\text { A Taxa de desvalorização da moeda: } & 1970 \quad 14 \% \\ 1971 & 10 \%\end{array}$

A percentagem aceitável de dividendos do acionista: $12 \%$ a.a.

Nota: Sendo uma companhia de capital aberto, consideramos dividendos pagos até $6 \%$ deduzíveis do lucro tributável. ${ }^{1}$

A alíquota do Impôsto sôbre a Renda. $\quad 30 \%$

Nota: Para a simplificação do exemplo, não consideramos a alternativa de incentivos fiscais sôbre a aplicação do Impôsto sôbre a Renda.

A Reserva Legal (até $20 \%$ do capital) $-5 \%$ sôbre o lucro antes de sua distribuição.

Nota: Consideramos a Reserva Legal uma parte integrante do capital próprio da emprêsa.

1 Artigo 9 do Decreto-lei $n^{\circ} 157$, de 20/2/1967. 
- Dedutibilidade do custo de manutenção do capital de giro próprio $^{2}$ - até $20 \%$ do lucro tributável.

- A Participação da Diretoria no lucro - $10 \%$.

Vamos, então, ao nosso exemplo, em três circunstâncias diferentes, ou seja, o recurso adicional no capital a ser utilizado para:

- aumento de ativo circulante;

- aumento de ativo imobilizado, e

- substituição do capital de terceiros.

\section{Capital Adicional para Aumento do Ativo Circulante}

A subscrição externa do capital no valor de $\operatorname{Cr} \$ 1.000,00$ foi efetuada em $1^{\circ}$ de janeiro de 1970 . Para não complicar desnecessàriamente o exemplo, consideramos que a chamada foi feita ao valor nominal e que não houve despesas para com o lançamento de novas ações. Suponhamos que o capital adicional será utilizado exclusivamente para aumentar o ativo circulante. Assim, teremos:

$1 .^{\circ}$ de Janeiro de 1970

Realizável:

Ativo Circulante $\operatorname{Cr} \$ 1.000,00$
Não Exigível:

Capital:

$\operatorname{Cr} \$ 1.000,00$

A função mínima do lucro numa economia inflacionária é manter a integridade do capital contra a desvalorização da moeda. O nôvo capital de $\mathrm{Cr} \$ 1.000,00$, efetuado em $1^{\circ}$ de janeiro de 1970 , deverá ser protegido contra a desvalorização da moeda que supomos seja de $14 \%$ ao ano. Assim sendo, o lucro líquido do período deverá ser, no mínimo, de $\mathrm{Cr} \$ 140,00(\mathrm{Cr} \$ 1.000,00 \times$ $\times 14 \%$ ) para se manter o poder aquisitivo do capital adicional. A segunda função básica do lucro é proporcionar recursos financeiros para cumprimento de obrigações legais e estatutárias. Em nosso exemplo, isto significa os dividendos de ..... Cr\$ $120,00(\mathrm{Cr} \$ 1.000,00 \times 12 \%)$, a participação da diretoria 2 Artigo 19 do Decreto-lei $n^{\circ} 401$ de 31/12/1968, artigo 4 do Decreto-lei $n^{\circ} 433$ de 23/1/1969, Portaria GB n? 31 de $31 / 1 / 1969$, do Ministério da Fazenda e artigos 10 e 11 do Decreto-lei $n^{\circ} 1.089$ de $2 / 3 / 1970$. 
em $10 \%$ do lucro do exercício e a provisão para o Impôsto de Renda. A terceira função principal do lucro é gerar os fundos suficientes para as atividades produtivas e comerciais da emprêsa para o futuro próximo. Neste exemplo, supomos que não há necessidade imediata de aquisição de bens adicionais de produção porque o nível operacional da emprêsa ainda não atingiu a capacidade máxima dos equipamentos.

O balanço em 31 de dezembro de 1970, portanto, deverá apresentar os seguintes valôres como conseqüência do aumento do capital através da subscrição:

31 de dezembro de 1967

antes da distribuição do lucro

Realizável:

Ativo Circulante

Total Ativo

$\mathrm{Cr} \$ 1.433,33$

$\operatorname{Cr} \$ 1.433,33$
Não Exigivel:

Capital

Lucro

Total Passivo
$\operatorname{Cr} \$ 1.000,00$ 433,33

Cr\$1.433,33

a) Para manutenção da integridade do capital investido:

Cr\$1.000,00 $\times 14 \%$ (taxa de desvalorização da moeda) $=\mathrm{Cr} \$ 140,00$ (inclusive a Reserva Legal)

Para apropriar 5\% do lucro tributável à Reserva Legal:

$0,05 \times(X=$ lucro tributável $)$

b) Para proporcionar os recursos monetários para dividendos: Cr $\$ 1.000,00 \times 12 \%$ (percentagem esperada dos investidores) $=\mathrm{Cr} \$ 120,00$

c) Para apropriar $10 \%$ do lucro tributável à Participação da Diretoria no resultado do exercício: $0,10 \times(\mathrm{X}=$ lucro tributável)

d) Para apropriar 30\% do lucro tributável à Provisão para o Impôsto sôbre a Renda: $0,30 \times(X=$ lucro tributável $)$

Combinando os fatôres acima, o lucro tributável (X) é calculado como segue:

$$
\begin{aligned}
X & =a)+b)+c)+d) \\
& =\operatorname{Cr} \$ 140,00+\operatorname{Cr} \$ 120,00+0,10 X+0,30 X \\
& =\operatorname{Cr} \$ 433,33
\end{aligned}
$$


Assim sendo, o Balanço em 31 de dezembro de 1970, após a distribuição do lucro, apresentará a seguinte posição:

31 de dezembro de 1970

após a distribuição do lucro

Realizável:

Ativo Circulante

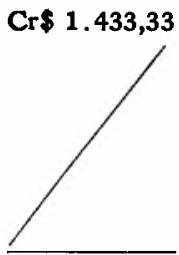

Não Exigível:

Capital

Cr\$1.000,00

Reserva Legal

21,67

Reserva p/Aumento

do Capital

118,33

Exigível:

Dividendos a Pagar $\quad 120,00$

Credores - Diretores 43,33

Imp. de Renda a Pagar $\quad 130,00$

Total Ativo

Cr $\$ 1.433,33$

Total Passivo

Cr $\$ 1.433,33$

Vejamos que, para o primeiro ano (1970), do aumento de capital de Cr\$ $1.000,00$, a emprêsa deve estar em condições de produzir o resultado econômico adicional de $\mathrm{Cr} \$ \mathbf{4 3 3 , 3 3}$.

Supomos que a margem média de contribuição, ou seja, o resultado operacional antes de despesas fixas, ${ }^{3}$ desta emprêsa é de $20 \%$ sôbre vendas: então, para obter o resultado adicional de Cr\$ 433,33 a emprêsa deve aumentar as vendas em:

Resultado Econômico Adicional de Cr\$433,33

Margem de Contribuição de $20 \%$
$=$ Vendas Adicionais Necessárias de Cr\$2.166,66

Em têrmos do poder aquisitivo de cruzeiro no início do ano, as vendas adicionais de $\mathrm{Cr} \$ 2.166,66$ representariam:

Cr\$ 2.166,66

$$
\overline{100 \%+14 \% \text { (desvalorização) } \times 1 / 2}=\mathrm{Cr} \$ 2.024,92
$$

Se, em virtude tanto dos fatôres mercadológicos como da limitação da capacidade de produção, a emprêsa não puder alcançar

3 "A margem de contribuiçåo, conhecida também por 'contribuição para - lucro', 'contribuição para cobrir o custo fixo e proporcionar lucro', 'contribuição para o custo fixo', 'saldo marginal', 'receita marginal', 'lucro marginal', e outras denominaçóes, se refere à diferença entre o preço de venda e o custo variável..." (PINTo DiAs, Ivan. Algumas Observaçōes sôbre a Margem de Contribuição. Revista de Administração de Emprêsas, setembro de 1967, p. 81). 
êsse nivel de vendas adicionais, ela não poderá cumprir tôdas as exigências (itens $a, b, c$ e d no exemplo acima) perante a subscrição externa de capital de $\operatorname{Cr} \$ 1.000,00$.

Igualmente importante é examinar se o ativo circulante adicional é suficiente para poder realizar as vendas adicionais necessárias. Suponhamos que a rotação média de vendas sôbre $o$ ativo circulante desta emprêsa é três por ano. Então, o acréscimo do ativo circulante de $\mathrm{Cr} \$ 1.140,00$ poderá proporcionar as vendas adicionais de até $\mathrm{Cr} \$ 3.420,00$. Neste aspecto de relação VendasAtivos, não vemos dificuldade para 1970 , porque as vendas adicionais necessárias de $\operatorname{Cr} \$ 2.166,66$ são bem inferiores a $\operatorname{Cr} \$$ $3.420,00$.

Prosseguimos com o mesmo exemplo no segundo ano (1971). O Balanço, em 31 de dezembro de 1971, apresenta os seguintes valôres, como consequiência do aumento de capital de ...... Cr\$ 1.000,00 efetuado no início do ano anterior:

31 de dezembro de 1971

antes da distribuição do lucro

Realizável:

Ativo Circulante

\begin{tabular}{c|c} 
Cr\$1.488,79 & $\begin{array}{l}\text { Não Exigível: } \\
\text { Capital } \\
\text { Reserva Legal } \\
\text { Lucro }\end{array}$ \\
\hline Cr\$1.488,79 & $\begin{array}{l}\text { Total Passivo }\end{array}$
\end{tabular}

Cr $\$ 1.118,33$

21,67 .

348,79

Total Ativo

e) O Capital foi aumentado, incorporando-se a reserva para tal finalidade de Cr\$118,33 (ver o Balanço de 31 de dezembro de 1970, após a distribuição do lucro).

f) Para manutenção da integridade do capital investido:

Cr\$1.140,00 × 10\% (taxa de desvalorização da moeda em $1971)=\operatorname{Cr} \$ 114,00$.

A eqüidade do capital adicional deverá chegar a $\operatorname{Cr} \$ 1.254,00$, no fim de 1971, para manter o poder aquisitivo do investimento inicial de $\mathrm{Cr} \$ 1.000,00$, em $1^{\circ}$ de janeiro de 1970 $(=\mathrm{Cr} \$ 1.000,00 \times 114 \% \times 110 \%)$.

g) Para proporcionar os recursos monetários para dividendos: $\mathrm{Cr} \$ 1.118,33 \times 12 \%$ (percentagem de rendimento esperada dos investidores) $=\mathrm{Cr} \$ 134,20$. 
h) Para considerar dedutíveis do Impôsto sôbre a Renda os dividendos pagos até $6 \%$ referentes ao aumento de capital de Cr\$ 1.000,00:

$\mathrm{Cr} \$ 1.000,00 \times 6 \%=\mathrm{Cr} \$ 60,00$

i) Para abater o custo de manutenção do capital de giro próprio, até $20 \%$ do lucro antes do abatimento:

O saldo inicial do capital circulante líquido em 1971 é de $\mathrm{Cr} \$ 1.140,00$. Conseqüentemente, o custo de manutenção de capital de giro próprio é $\mathrm{Cr} \$ 114,00(10 \%$ de desvalorização de moeda sôbre Cr $\$ 1.140,00)$. Entretanto, êste valor deverá ser ajustado a $20 \%$ do lucro tributável que é o máximo permitido por lei.

j) Para apropriar $10 \%$ do lucro à Participação da Diretoria no resultado do exercício.

k) Para apropriar $30 \%$ do lucro tributável à Provisão para o Impôsto sôbre a Renda.

Lucro do Exercício

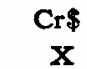

- Dividendos Pagos até $6 \%$

- Reserva para Manutenção do Capital de Giro

Lucro Tributável

Provisão para Impôsto sôbre a renda $(30 \%)$

$0,24 X-18,00$

Demonstramos abaixo a posição do lucro e sua destinação:

Lucro do Exercício

Cr\$ Cr\$ Cr\$

Reserva Legal

17,44

Reserva p/Aumento do Capital

26,80

Reserva p/Manutenção do Capital de Giro

69,76

114,00

Participação da Diretoria

34,88

Dividendos Declarados

134,20

Provisão para o Impôsto s/Renda

Total

65,71

$\overline{348,79} \quad \overline{348,79}$

Assim, teremos a seguinte posição do Balanço de 1971, após a distribuição do lucro: 
Realizável

Ativo Circulante

Total Ativo

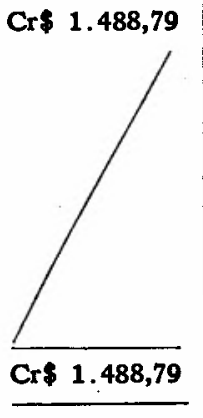

Não Exigível

Capital

Reserva Legal

Reserva p/aumento do Capital

Reserva p/Manutenção do Capital de Giro

Cr\$ 1 . 118,33

39,11

26,80

69,76

Exigivel:

Dividendos a Pagar Credores - Diretores

Imp. de Renda a Pagar

Total Passivo

Cr $\$ 1.488,79$

Suponhamos que a margem média da contribuição continua sendo de $20 \%$ como em 1970 . As vendas, a fim de atingir o acréscimo necessário de $\mathrm{Cr} \$ 348,79$, no resultado econômico de 1971 , deverão aumentar em $\mathrm{Cr} \$ 1.743,95$. Em têrmos de poder aquisitivo em cruzeiros na época da chamada de capital (início de 1970), estas vendas adicionais equivaleriam a:

$$
\frac{\operatorname{Cr} \$ 1.743,95}{114 \%\left(1+\frac{10 \%}{2}\right)}=\operatorname{Cr} \$ 1.456,93
$$

Agora, analisaremos a relação Vendas-Ativos. Comparando os valôres de dois exercícios, teremos a seguinte relação:

\begin{tabular}{cccc} 
Exercício & $\begin{array}{c}\text { Acréscimo do } \\
\text { Ativo Circulante }\end{array}$ & $\begin{array}{c}\text { Acréscimo Necessário } \\
\text { de Vendas }\end{array}$ & Coeficiente \\
\hline 1970 & Cr\$1.140,00 & Cr\$2.166,66 & 1,90 \\
1971 & Cr $\$ 1.254,00$ & Cr\$1.743,95 & 1,39
\end{tabular}

E importante observar que os baixos coeficientes (o coeficiente médio presumido neste exemplo é 3) da relação Vendas-Ativos foram motivados pela aplicação do nôvo capital no ativo circulante, que tem apresentado uma folga substancial.

\section{Capital Adicional para Aumento do Ativo Imobilizado}

No exemplo anterior, suponhamos que o capital adicional será utilizado exclusivamente para aumentar o ativo circulante. Suponhamos que, agora, o aumento do capital seja dirigido para 
aquisições de ativo imobilizado, depreciável em 10 anos, em vez de ativo circulante. Assim sendo, teremos as seguintes posições patrimoniais:

$1 .^{\circ}$ de janeiro de 1970

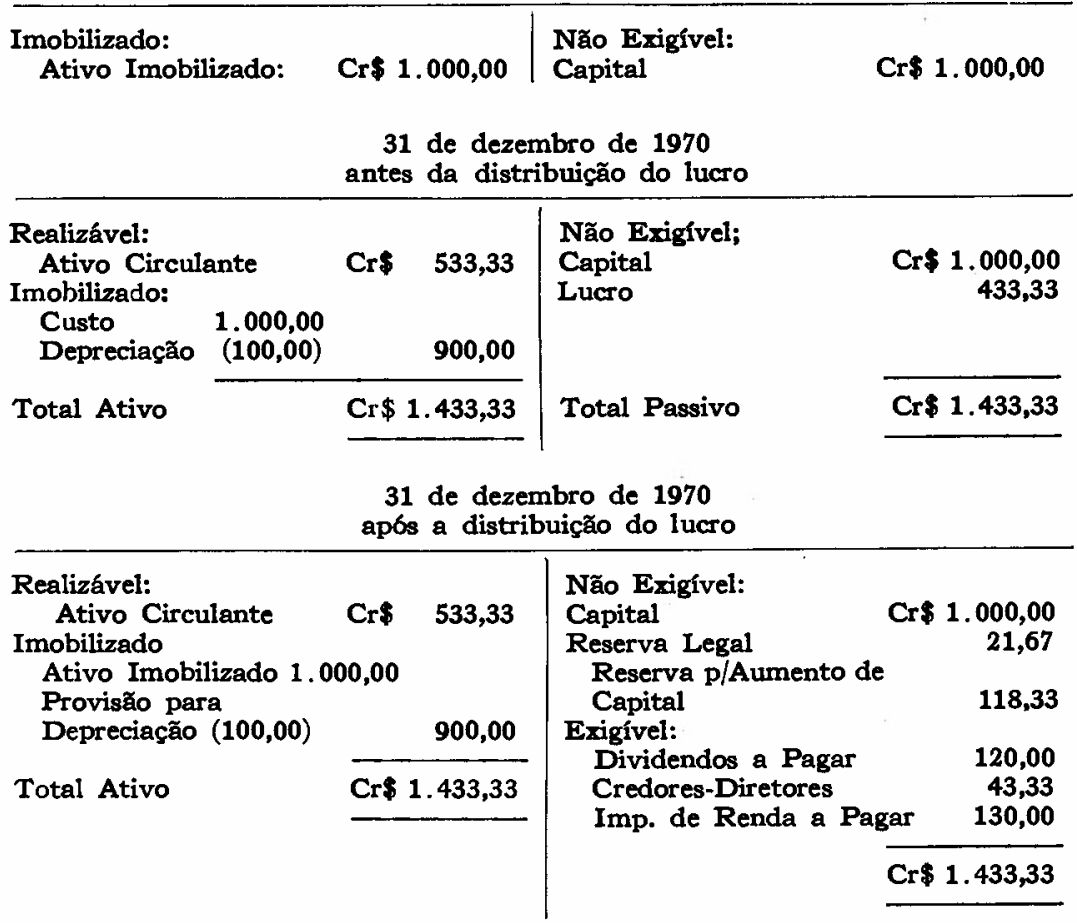

Numa economia inflacionária, o investimento em ativo imobilizado é considerado, em princípio, como hedge (proteção) contra desvalorização da moeda. A eqüidade do nôvo capital, então, é supostamente protegida contra a erosão do poder aquisitivo da moeda, quando êle é aplicado no ativo imobilizado e quando sua valorização acompanha a inflação. Conforme as legislações fiscais em vigor, entretanto, esta proteção é permitida através de índices oficiais de correção monetária do ativo imobilizado sòmente no próximo exercício. Por outro lado, o lucro, neste caso, em comparação com o primeiro exemplo de aplicação em ativo circulante, deverá refletir êste fator, considerando a depreciação do nôvo ativo imobilizado como despesa adicional.

Convencionamos $\mathrm{X}$ como o lucro antes de deduzir a despesa com depreciação sôbre o nôvo ativo imobilizado. A equação será: 
$\mathrm{X}=\mathrm{Cr} \$ 140,00$ desvalorização do capital

$+\operatorname{Cr} \$ 100,00$ depreciação s/ nôvo ativo imobilizado

$+\operatorname{Cr} \$ 120,00$ dividendos a declarar

$+0,1(X-100,00)$ participação da Diretoria

$+0,3(X-100,00)$ provisão para Impôsto s/Renda então $\mathrm{X}=\mathrm{Cr} \$ 533,33$, e, portanto, o lucro proveniente de vendas é $\operatorname{Cr} \$ 307,33$ (Cr\$ 533,33 - Cr $\$ 100,00$ Depreciação - . . . Cr\$ 126,00 Valorização em $14 \%$ do Imobilizado).

A emprêsa, portanto, deve aumentar as vendas, no mínimo, em Cr $\$ 1.536,66$, para obter o resultado adicional de $\mathrm{Cr} \$ 307,33$, supondo a margem de contribuição de $20 \%$. Se o coeficiente Vendas-Ativos Circulantes desta emprêsa é três, o ativo circulante deverá aumentar em $\operatorname{Cr} \$ 512,22(\mathrm{Cr} \$ 1.536,66+3)$.

Observamos que o aumento de ativo circulante em 1970 foi sòmente de $\operatorname{Cr} \$ 240,00$. Isto quer dizer que a emprêsa deveria ter folga de ativo circulante em $\mathrm{Cr} \$ 272,22$, no mínimo, antes da realização da chamada de capital, ou a emprêsa não poderá aumentar as vendas até o nível necessário, por falta de capital de giro.

Vamos examinar a posição do segundo ano após a chamada de capital:

31 de dezembro de 1971

após a distribuição do lucro

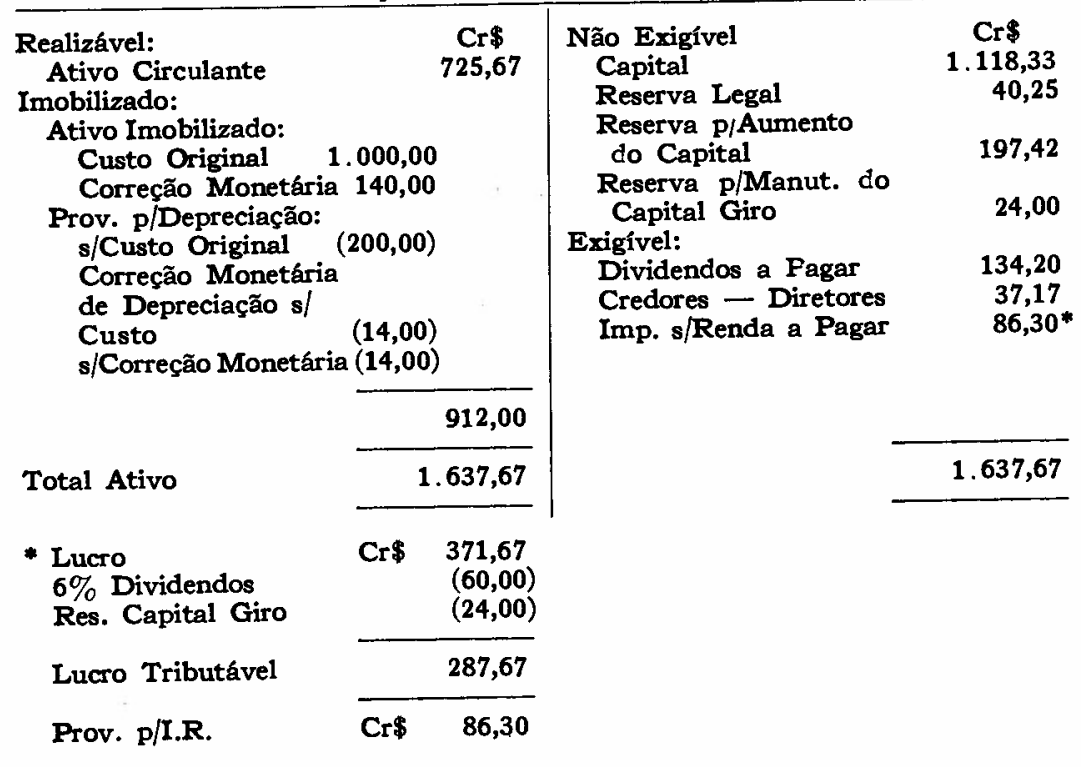


Notamos que no fim de 1971 , o ativo circulante é de $\mathrm{Cr} \$ 468,00$ que corresponde a sua necessidade para 1971 da ordem de .. Cr\$ 467,45

$$
\left(=\frac{\text { Lucro Cr } \$ 371,67-\text { Valorização do Ativo Imobilizado Cr } \$ 91,20}{\text { M.C. } 0,20 \times 3 \text { Coeficiente Vendas/Ativo Circulante }}\right) .
$$

\section{Capital Adicional para Substituir Empréstimos}

O terceiro exemplo é de liquidação de empréstimos com novos recursos do aumento de capital. Neste exemplo, consideramos que o custo de empréstimo é igual à desvalorização de cruzeiro. Eis as posições patrimoniais:

$1 .^{\circ}$ de janeiro de 1970

\begin{tabular}{|c|c|c|c|c|}
\hline $\begin{array}{l}\text { Realizável: } \\
\text { Redução de Emprést. }\end{array}$ & $\mathrm{Cr} \$ 1.000,00$ & $\begin{array}{l}\text { Não Exigível: } \\
\text { Capital }\end{array}$ & \multirow{2}{*}{\multicolumn{2}{|c|}{$\frac{C r \$ 1.000,00}{C r \$ 1.000,00}$}} \\
\hline Total Ativo & $\mathrm{Cr} \$ 1.000,00$ & & & \\
\hline \multicolumn{5}{|c|}{$\begin{array}{c}31 \text { de dezembro de } 1970 \\
\text { após a distribuição do lucro }\end{array}$} \\
\hline Realizável: & $\mathrm{Cr} \$$ & Não Exigível: & $\mathrm{Cr} \$$ & $.000,00$ \\
\hline . & & $\begin{array}{l}\text { Reserva p/Aumento de } \\
\text { Capital } \\
\text { Exigivel: } \\
\text { Juros a Pagar s/Em- } \\
\text { préstimos } \\
\text { Imp. Renda a Pagar } \\
\text { s/Empréstimos } \\
\text { Dividendos a Pagar } \\
\text { Credores - Diretores } \\
\text { Impósto s/Renda a P }\end{array}$ & Pagar & $\begin{array}{r}118,33 \\
(140,00) \\
42,00 \\
120,00 \\
43,33 \\
88,00\end{array}$ \\
\hline Total Ativo & $1.293,33$ & Total Passivo & & $.293,33$ \\
\hline
\end{tabular}

O lucro adicional do ano de 1970 , como consequiência da chamada de capital é de $\mathrm{Cr} \$ 433,33$, o que inclui a receita implícita de $\mathrm{Cr} \$ 140,00$, referente a não-pagamento de juros sôbre empréstimos e à despesa implícita de $\operatorname{Cr} \$ 42,00$ do impôsto de renda sôbre $\operatorname{Cr} \$ 140,00$, dando o resultado líquido de $\operatorname{Cr} \$ 98,00$. O lucro vegetativo necessário oriundo de operações mercantis, então, é de Cr\$ 335,33. A margem de contribuição sendo de 
$20 \%$, as vendas deverão ser aumentadas em Cr\$1.676,66. O ativo circulante de $\mathrm{Cr} \$ 1.140,00$ é idêntico ao primeiro caso de aplicação do aumento de capital em ativo circulante. A posição do segundo ano é a seguinte:

31 de dezembro de 1971

ap6s a distribuição do lucro

\begin{tabular}{|c|c|c|c|}
\hline $\begin{array}{l}\text { Realizável: } \\
\text { Ativo Circulante } \\
\text { Reduçăo de Emprést. }\end{array}$ & Cr\$ $\begin{array}{r}416,67 \\
1.000,00 \\
\end{array}$ & $\begin{array}{l}\text { Não Exigível: } \\
\text { Capital } \\
\text { Reserva Legal } \\
\text { Reserva p/Aumento do } \\
\text { Capital } \\
\text { Reserva p/Manut. do } \\
\text { Capital de Giro } \\
\text { Exigivel: } \\
\text { Juros a Pagar s/Em- } \\
\text { préstimos } \\
\text { Imp. Renda a Pagar } \\
\text { s/Empréstimos } \\
\text { Dividendos a Pagar } \\
\text { Credores - Diretores } \\
\text { Prov. p/Imp. s/Renda }\end{array}$ & $\begin{array}{r}\text { Cr\$ } 1.118,33 \\
40,56 \\
81,11 \\
14,00 \\
\\
(100,00) \\
30,00^{*} \\
134,20 \\
37,67 \\
60,80^{*}\end{array}$ \\
\hline Total Ativo & $1.416,67$ & Total Passivo & $1.416,67$ \\
\hline $\begin{array}{l}\text { * Lucro } \\
\text { 6\% Dividendos } \\
\text { Reserva Capital Giro }\end{array}$ & $\begin{array}{l}376,67 \\
(60,00) \\
(14,00)\end{array}$ & & \\
\hline Lucro Tributável & Cr $\$ \quad 302,67$ & & \\
\hline Prov. p/Imp. Renda & 90,80 & & \\
\hline
\end{tabular}

O lucro mínimo desejado para 1971 é $\mathrm{Cr} \$ 376,67$, o que inclui Cr $\$ 100,00$ de reversão de juros e $\operatorname{Cr} \$ 30,00$ do impôsto de renda que teriam sido incorridos se os empréstimos tivessem continuado. As vendas necessárias ( $\mathrm{Cr} \$ 1.533,35)$ encontrarão o amplo capital de giro (Cr\$511,12 necessário vs. Cr\$ 1.254,00 real).

\section{Conclusão}

Nos exemplos dêste artigo, demonstramos os efeitos da subscrição externa de capital sob diversas hipóteses. No primeiro ano (1970) do segundo caso de aplicação no ativo imobilizado, a chamada de capital necessitou uma retaguarda de capital de giro antes do lançamento de novas ações. Em todos os casos, as responsabilidades acionárias, estatutárias e fiscais vão sem- 
pre além de simples distribuição de dividendos. É importante que o empresário analise as possibilidades mercadológicas e as perspectivas de rentabilidade sôbre o incremento necessário de vendas, antes de decidir fazer um aumento de capital, a fim de assegurar os recursos necessários para com as responsabilidades fiscais, estatutárias e acionárias.

$\mathrm{Na}$ realidade, as aplicações de recursos da subscrição externa de capital poderão ser múltiplas - combinação das três hipóteses citadas neste artigo. Esperamos que o raciocínio e a análise feitas neste artigo sejam úteis para estudos mais complexos de novos lançamentos de ações, chamando a atenção dos empresários para as suas responsabilidades de retribuir os novos acionistas e para a conscientização e cumprimento das mesmas.

Você acredita em reformas administrativas? Ou você acha que há reformas e reformas?

Em Laboratório de Sensibilidade de Fela Moscovici, editado pela Fundação Getúlio Vargas, o problema é analisado exaustivamente. As reformas, segundo a autora, não passam de novos arranjos de estruturas e relações, enquanto o laboratório de sensibilidade, amplamente testado nos Estados Unidos, opera dinâmica e profunda mudança na administração. 